\title{
Initial Results of Adiabatic Compressed Air Energy Storage (CAES) Dynamic Process Model
}

\author{
Tomi Thomasson Matti Tähtinen \\ VTT Technical Research Centre of Finland Ltd., Finland, tomi . thomasson@vtt. fi
}

\begin{abstract}
The amount of wind and solar generation has seen exponential growth during the recent decades, and the trend is to continue with an increased pace. Due to the intermittency of the resources, a threat is posed on grid stability and a need created for regulation. One solution to control the imbalance between supply and demand is to store the electricity temporarily, which in this paper was addressed by implementing a dynamic model of adiabatic compressed air energy storage (CAES) with Apros dynamic simulation software. Based on the literature review, the existing models due to their simplifications do not allow transient situations e.g. start-ups to be studied, and despite of its importance, part-load operation has not been studied with sufficient precision. The implemented model was validated against analytical calculations (nominal load) and literature information (part-load), showing considerable correlation. By incorporating the system with wind generation and electricity demand, the grid operation of CAES was studied. In order to enable this, the start-up and shutdown sequences based on manufacturer information were approximated in dynamic environment, to the authors' best knowledge, for the first time. The initial results indicate that the modularly designed model offers an accurate framework for numerous studies in the future.
\end{abstract}

Keywords: energy storage, compressed air energy storage, dynamic simulation, numerical simulation

\section{Introduction}

The rise of variable renewable energy (VRE) has been remarkably rapid during the past decades; not only it is considered an integral part of the current energy system, its importance in the future cannot be highlighted enough (World Energy Council, 2013). This new generation capacity mainly consisting of solar and wind power lacks inertia and carries the burden of intermittency, meaning that the availability of the resource varies in both short and long term (Barnhart et al., 2013). Both solar and wind have seen the installed capacity increasing exponentially during the recent decade, but the share of VRE generation in the electricity grids of the large markets is still considerably modest (REN21, 2015). Due to intermittency, technical barriers e.g. disturbances in voltage magnitude and delivery frequency may create economic barriers in transition to greater share of VRE generation (Sundararagavan and Baker, 2012; SBC Energy Institute, 2013). For example, curtailment of around $40 \%$ of the total generation has been reported in the wind farms of China (Christiansen and Murray, 2015).

Solutions to counter the effects of intermittency range from demand side response e.g. time-of-day electricity pricing to utility side response, amongst which the compressed air energy storage (CAES) belongs. The operating principle of CAES is best described as mechanical conversion of electricity into the form of pressurized air. Electricity is stored during the hours of low consumption and supplied back to the grid once the demand has increased. CAES as a process is fundamentally dynamic, as the system is able to ramp twice or three times as fast as the conventional alternatives (Bradshaw, 2000) and is designed to accommodate multiple start-ups and shutdowns on a daily basis (Schulte et al., 2012). The two existing CAES systems are based on the needs of the conventional energy system. While the Huntorf CAES was initially constructed to provide black start capability for nuclear power plants (Succar and Williams, 2008), the McIntosh CAES fills the deficit between the capacity of a coal power plant and the demand (Arsie et al., 2007).

The deficiency of diabatic CAES technology introduced above is the requirement of an external source of heat, typically natural gas, leading to carbon dioxide emissions. An alternative is to recover, store, and utilize the heat of compression, which is the working principle of the adiabatic configuration (Kreid, 1976). This approach is generally accepted to lead to notably higher cycle efficiency compared to diabatic CAES (Hartmann et al., 2012), but despite extensive research activities (Zunft, 2015), the technology is only nearing demonstration stage (Airlight Energy, 2016). In order to overcome challenges mainly related to temperature limitations in the compressor technology (De Biasi, 2009) and storing the thermal energy, low temperature concept has been recently proposed (Wolf and Budt, 2014). As the cycle efficiency is not governed by the Carnot efficiency, storing the heat at a lower temperature level 
leads to a relatively small efficiency penalty, but allows faster start-up due to lower thermal inertia (Freund et al., 2012). This, along the economic limitations (Zunft, 2015) and the required flexibility in the electricity market (Wolf and Budt, 2014), supports the idea of developing downscaled systems.

\section{Methodology}

As CAES is comparable to open Brayton cycle gas turbine, great understanding of the process and its components readily exists. However, the need for detailed dynamic simulations has recently been pointed out (Budt et al., 2016). This chapter presents the background for the model development of this paper.

\subsection{The lack of dynamic features in the existing models}

Although dynamic as term well describes the operation of CAES, the past efforts in literature have largely focused on the dynamic cavern operation (Nielsen and Leithner, 2009; Khaitan and Raju, 2013). Detailed studies related to turbomachinery have scarcely been conducted, even then typically on component level based on comprehensively studied analytical approaches (Luo et al., 2016). Furthermore, the use of constant material properties limits the accuracy of several of the models; although at times justified, the error in one property is also present in the other.

As the idea of combining energy storage with intermittent generation is well understood, logic systems related to CAES have been presented in literature (Arsie et al., 2007; Zhao et al., 2015). The limitation in steady-state simulation is that the logic systems are often developed by assuming fixed time windows; a disturbance occurs whenever it is selected to take place. In reality, there is a clear need to operate the storage depending on the supply and demand while maintaining the system as efficient as possible. This is only achieved by means of control engineering, which seemingly has only been covered by Budt et al. (2012) so far.

\subsection{Apros dynamic simulation software}

Apros is a dynamic simulation tool and modelling software, which includes tools for design, evaluation and testing of various types of processes (Fortum and VTT). As suggested by Figure 1, Apros enables the possibility for detailed control and operation strategy development besides process simulation. Apros has commonly found applications in power plant simulations, but due to comprehensively validated component model library and the possibility for userdefined components, the software has more recently

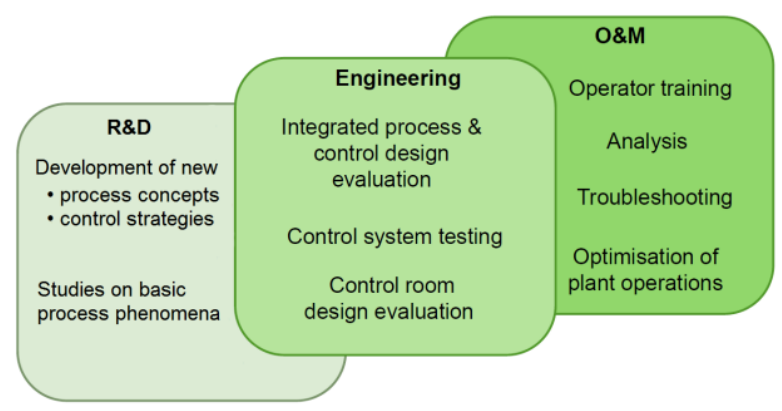

Figure 1. Apros and its various applications.

been successfully extended to the field of energy storage (Tähtinen et al., 2016).

The model hierarchy of Apros consists of three levels: diagrams, process component level and calculation level. The user often operates on the diagram level, constructing the model out of the process components such as pipes, valves and heat exchangers; each operating analogous to their concrete counterpart. When included in the model, the process component automatically creates its necessary calculation level objects, the nodes and branches. With these objects, the conservation equations for mass, momentum and energy are solved. Several accuracy levels for solving the thermohydraulic solution are available; for the composition AIR used in the dynamic model, representing ideal gas mixture of oxygen and nitrogen, only the homogenous flow model may be selected.

\subsection{Implementation of the dynamic model}

The dynamic model is developed according to the lowtemperature principles introduced by Wolf and Budt, (2014) leading to a system with a relatively low compression and expansion power. Most importantly, the goal is to create a flexible model, allowing easy scalability with future studies in mind. In order to validate the model, the initial conditions are based on thermodynamic analysis, for which the resulting parameters are shown in Table 1. Values for certain constants such as polytropic efficiencies and nominal storage pressure are obtained from literature (De Biasi, 2009; Barbour et al., 2015). The layout of the model, simplified in Figure 2, can be considered to consist of the following subsystems:

- Turbomachinery

- Thermal energy storage (TES)

- Compressed air storage (CAS)

- Control and logic system 


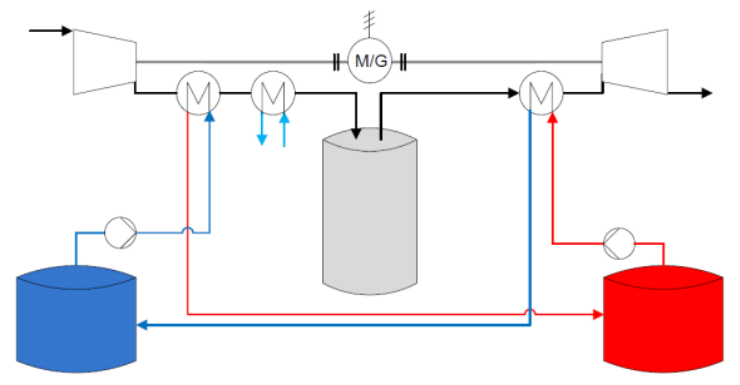

Figure 2. Simplified illustration of the model layout and the flow schemes: air (black), thermal oil (blue and red) and water (light blue).

As fixed-speed compressor trains have prevalently been used with CAES, variable guide vanes (VGV) have generally been selected for compressor capacity control (Dresser-Rand, 2015). In principle, the guide vanes allow load changes by shifting the operating point. After evaluation, the compressor map presented by Brasz (1996) was selected and introduced to the model as nominal polytropic efficiency and nominal mass flow rate as a function of guide vane angle. Each of the compressors is during periods of low mass flow rates effectively protected from surge by control principles presented by Brun and Nored (2008).

The expander train of CAES can be operated with either fixed or varying inlet pressure (Weber, 1975). Similar to the existing systems, throttle valve placed upstream the expander train is selected to reduce the pressure of the air discharged from the storage, allowing capacity control with an increased efficiency at part-load. The turbomachinery is selected to be connected on a single shaft and to share the electric motor-generator unit, preventing charging and discharging from taking place simultaneously. The clutches, enabling the required loading and unloading of the electric machine, are implemented by using a number of switch and set dominant latch components.

The TES is implemented based on the previous work of Hakkarainen and Tähtinen (2016), in principle solving the mass and energy balances in calculation level. Due to the approach, the tanks are assumed isothermal and only single-phase fluids can be realistically evaluated. Therminol VP-1 (Solutia, 1999) due to its suitable temperature range is selected as the heat transfer fluid. The heat exchangers are dimensioned with information about typical configurations and operating parameters (Freund and Moreau, 2012). During the charging process, heat considered as excess is left to the process. To overcome this issue, auxiliary heat exchanger applied by many including (De Biasi, 2009) is placed upstream to CAS. For the CAS representing an artificial storage tank, heat losses based on conduction and convection mechanisms are implemented.

The combined control and logic system of the model has four primary tasks: to control both
Table 1. Key input parameters of the model.

\begin{tabular}{|l|l|}
\hline \multicolumn{1}{|c|}{ Parameter } & Value \\
\hline General & \\
\hline Nominal charging power & $25.41 \mathrm{MW}$ \\
\hline Nominal discharging power & $14.96 \mathrm{MW}$ \\
\hline Nominal cycle efficiency & $58.87 \%$ \\
\hline Charging period ratio & 1.0 \\
\hline Compressor train & \\
\hline Number of stages & 4 \\
\hline Nominal mass flow rate & $35 \mathrm{~kg} / \mathrm{s}$ \\
\hline Nominal pressure ratio, stage 1 & 4.33 \\
\hline Nominal pressure ratio, stage $2-4$ & 3.4 \\
\hline Polytropic efficiency & $85 \%$ \\
\hline Expander train & \\
\hline Number of stages & 3 \\
\hline Nominal mass flow rate & $35 \mathrm{~kg} / \mathrm{s}$ \\
\hline Nominal pressure ratio, stages $1-3$ & 4.87 \\
\hline Polytropic efficiency & $85 \%$ \\
\hline TES & \\
\hline Nominal mass flow rate & varies per stage \\
\hline $\begin{array}{l}\text { Nominal heat transfer } \\
\text { effectiveness }\end{array}$ & $75-85 \%$ \\
\hline Nominal cold tank temperature & $25^{\circ} \mathrm{C}$ \\
\hline Nominal hot tank temperature & $188.8^{\circ} \mathrm{C}$ \\
\hline Storage capacity & $4 \mathrm{~h}$ \\
\hline CAS & \\
\hline Nominal temperature & $40^{\circ} \mathrm{C}$ \\
\hline Nominal pressure & $155 \mathrm{bar}$ \\
\hline Throttle pressure & $120 \mathrm{bar}$ \\
\hline Storage capacity & $4 \mathrm{~h}$ \\
\hline & \\
\hline
\end{tabular}

temperature and power, to actuate sequences, and to schedule the storage operation. Both the control tasks are implemented by using PI controllers, for which cascade loops are preferred due to smoother control action. For the power regulation, a limit is imposed on the controller set point gradient, which enables selecting the ramp rate based on actual concepts. The role of the sequences is to activate the individual control systems at the correct time during the start-up and shutdown, which are replicated using manufacturer information (Dresser-Rand, 2015). In addition, the storage operation is scheduled by using an interlocked predictive-reactive logic system. By applying a set of boundary conditions, the logic system allows the storage to be only operated at times when certain conditions e.g. deficiency in generation and sufficient storage pressure are met.

\subsection{Setup of the VRE framework}

As the existing CAES systems are based on predictable demand of storage operation, there is a need to develop more flexible storage operation strategies. For example, the daily and weekly cycles presented by Goodson (1992) are by no means viable for VRE. Furthermore, as the entire control system can only be effectively studied when combined with VRE, a simple 
wind farm model based on the fundamental equation of wind power (Manwell et al., 2009) and commercial wind turbine design (Vestas Wind Systems, 2004) is implemented in Apros.

The validated wind turbine model receives the wind data retrieved from NREL (2015) at a temporal resolution of one minute as an input through a gradient. Realistic representation of hourly load variation is retrieved from Fingrid (2015). As scaling of the storage system according the load curve is important, the load data is scaled to match the nominal output of the system accordingly (Le et al., 2012). In addition, the wind data is scaled in order to evaluate each part of the control system and the transitions between the operation modes.

\section{Results}

The challenge in model validation is the lack of available reference data. One should hence consider the observation of trends and physical phenomena more important than the absolute results. In Figure 3 and Figure 4, the values are consequently presented as relative expression; for the model as a comparison to nominal value and for the reference data as a comparison to maximum value.

Due to the implemented VGV component, the operation of the compressor train is first validated at the design point against the results of the thermodynamic analysis. The simulated power consumption and discharge temperature vary from the reference values for less than one percent for each compressor. At part-load, the created quadratic least squares polynomial fits at maximum create a relative error of $5 \%$ in both mass flow rate and polytropic efficiency. In addition, the start-up sequences are validated against the data of Dresser-Rand (2015), showing excellent correlation.

\subsection{Qualitative validation of the compressor train}

In order to validate the performance of compressor train, the results are compared to those of Budt et al. (2012) over the charging period. It should be noted that the reference model (ref) consists of eight compression stages, for which the detailed input parameters are not presented by the authors. The comparison is therefore done between the first and the last of the stages, and in addition, the fourth and the sixth stage of the reference model are visualized. In the developed model ( $\mathrm{sim})$, the compressor power consumption set point is fixed to 20 MW and the storage is charged for approximately four hours from 120 bars to 155 bars.

Figure 3 shows the comparison of compressor power consumption, from which two similarly shaped groups of curves can be observed. While the total power consumption remains constant, the relative power consumption of the first stages decreases. Simultaneously, the last stages show the greatest increase in relative power consumption, as indicated by

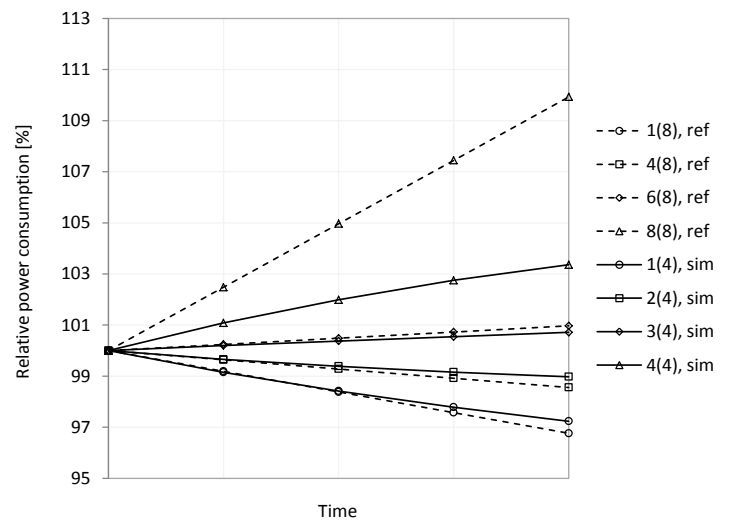

Figure 3. Simulated compressor power consumption compared to the results of Budt et al. (2012) over charging period.

both simulations. This is expected as the last stages also are subject to the relatively greatest increase in pressure ratio and hence are forced to operate farthest from the nominal point.

\subsection{Qualitative validation of the expander train}

The validity of the expander train is analyzed by comparing the relative pressure ratio at varied load rate against the results of Zhao et al. (2016) as shown in Figure 4. The authors study a system with two expansion stages, and explain that the decrease in pressure ratio is caused by the relationship between Stodola's ellipse law (Cooke, 1985) and mass flow rate. As the only constant discharge pressure in the expander train is the final point representing ambient conditions, the pressure ratio of the last stage should decrease with load rate, which is confirmed by both the simulations. However, with fixed inlet pressure operation mode, both the inlet and discharge pressure of the first stage decrease when operating at part-load. Therefore, the pressure ratio should largely stay unaffected by the variation in load rate, which is not shown by the results of Zhao et al. (2016).

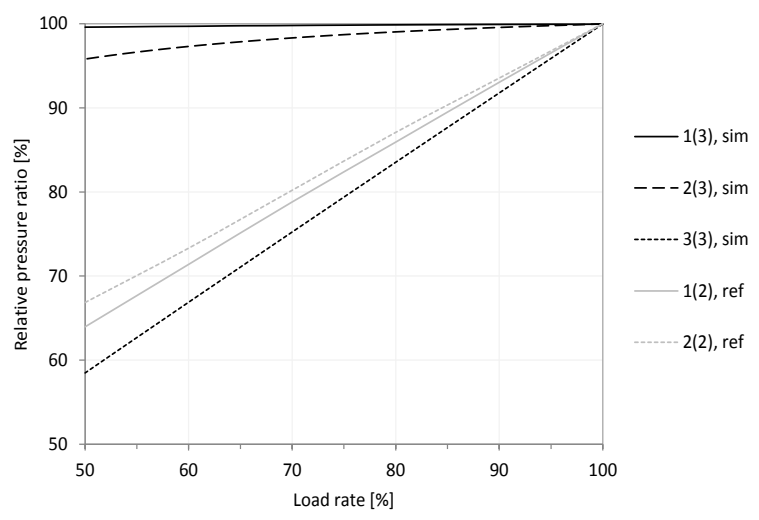

Figure 4. Simulated compressor power consumption compared to Zhao et al. (2016) over charging period. 


\subsection{Dynamic operation of the model}

In order to demonstrate the control system and its ability to regulate the power consumption and generation according the demand, in Figure 5 the model is operated for six hours in dynamic conditions. The upper subfigure shows the power charged to or from the grid depending on the excess or deficiency in wind generation, while the lower subfigure illustrates the state of CAS and TES. The following operation is primarily expected from the model during each of the temporal segments:

- Hour 1: charging

- Hour 2: no operation

- Hour 3: charging

- Hour 4: no operation

- Hour 5: discharging

- Hour 6: discharging

The results indicate that the expected operation is to large extent fulfilled. For example, during the first hour the lower subfigure of Figure 5 shows the CAS pressure steadily increasing, while thermal oil is transferred from the cold TES tank to the hot TES tank at elevated temperature level. The flat plateaus in the lower subfigure indicate that the system is not active, whereas the predominant flatness of the area curve in the upper subfigure suggests that the system is to large extent operated with nominal load rate.

The capability for accurate load following is highlighted particularly after $t=2 \mathrm{~h}$, where the system has to adjust the compressor power consumption nearly continuously. Furthermore, even though the operation is only scheduled by using ten-minute-ahead wind forecasts, the signals for unnecessary start-ups and shutdowns are largely avoided. Exceptions of this are visible for example slightly before $t=3 \mathrm{~h}$, where the system is needlessly shut down and started up multiple times consecutively. If the operation was to be scheduled optimally, the problem could be solved with additional interlock mechanisms e.g. inclusion of longer-term forecasts.

\section{Conclusions}

The initial results show that a dynamic model of adiabatic CAES has been successfully implemented with proven Apros dynamic simulation software. Due to a variety of readily validated process components as well as analytically developed and validated userdefined inclusions, both the steady-state and transient phenomena related to CAES can be studied in more detail than before.

Despite the simple model structure, more advanced phenomena e.g. compressor surge can be readily studied in future research. Model predictive control as well as improved forecasts and economic boundary conditions can be easily included in the existing logic system in order to enable more comprehensive case studies. The current TES model does not include heat losses, which currently limits the possibility for extended simulations. This, however, is to be corrected with the upcoming version of Apros, also allowing more accurate implementation of user-defined heat transfer fluids.
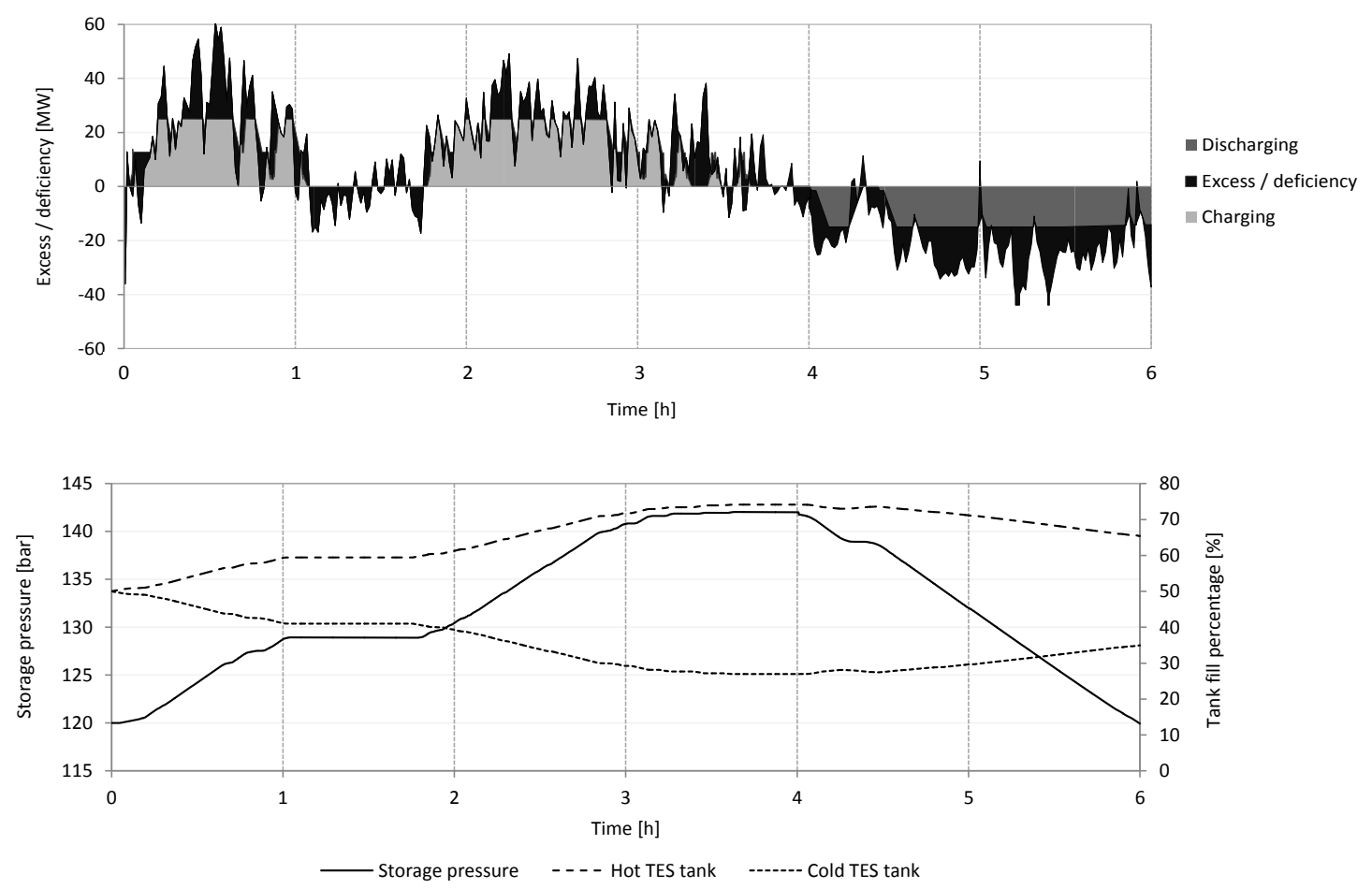

Figure 5. Grid operation of the dynamic model (upper subfigure) and the consequent variation in the state of CAS and TES. 


\section{References}

Airlight Energy. Advanced adiabatic compressed air energy storage [Online], 2016. http://www.airlightenergy.com/advanced-adiabaticcompressed-air-energy-storage/.

I. Arsie, V. Marano, M. Moran, G. Rizzo, and G. Savino. Optimal Management of a Wind/CAES Power Plant by Means of Neural Network Wind Speed Forecast. In European Wind Energy Conf. and Expo., 2007.

E. Barbour, D. Mignard, Y. Ding, and Y. Li. Adiabatic Compressed Air Energy Storage with packed bed thermal energy storage. Applied Energy 155: 804-815, 2015.

C. Barnhart, M. Dale, A. Brandt, and S. Benson. The energetic implications of curtailing versus storing solarand wind-generated electricity. Energy \& Environmental Science 6(10): 2804-2810, 2013.

D. Bradshaw. Pumped hydroelectric storage (PHS) and compressed air energy storage (CAES). In Power Engineer Society Summer Meeting, 2000.

J. Brasz. Aerodynamics of Rotatable Inlet Guide Vanes for Centrifugal Compressors. In International Compressor Eng. Conf: : 761-766, 1996.

K. Brun and M. Nored. Application guideline for centrifugal compressor surge control systems [Online], 2008. http://www.gmrc.org/documents/GMRCSurgeGuideline_0 00.pdf.

M. Budt, D. Wolf, R. Span, and J. Yan. A review on compressed air energy storage: Basic principles, past milestones and recent developments. Applied Energy 170: 250-268, 2016.

M. Budt, D. Wolf, and R. Span, Modeling a Lowtemperature Compressed Air Energy Storage with Modelica. In Proc. 9th Int. Modelica Conf:: 791-800, 2012.

C. Christiansen and M. Murray. Energy Storage Study [Online], 2015. http://arena.gov.au/files/2015/07/AECOMEnergy-Storage-Study.pdf.

D. Cooke. On Prediction of Off-Design Multistage Turbine Pressures by Stodola's Ellipse. J. Eng. Gas Turbines Power 107(3): 596-606, 1985.

V. De Biasi. Fundamental analyses to optimize adiabatic CAES plant efficiencies. Gas Turbine World 39(5): 2009.

Dresser-Rand. Dresser-Rand SMARTCAES - Compressed Air Energy Storage Solutions: Enabling Renewables [Online], 2015. https://www.dresser-rand.com/wpcontent/uploads/2015/01/caes.pdf.

Fingrid. Load and generation [Online], 2015. http://www.fingrid.fi/en/electricity-market/load-andgeneration/.

Fortum and VTT. Apros [Online]. http://www.apros.fi/filebank/193-Apros_Combustion.pdf.

S. Freund and R. Moreau. Commercial Concepts for Adiabatic Compressed Air Energy Storage. In 7th International Renewable Energy Conf. (IRES), 2012.

S. Freund, R. Schainker, and R. Moreau. Commercial Concepts for Adiabatic Compressed Air Energy Storage. In 7th International Renewable Energy Conf. (IRES), 2012 .
J. Goodson, History of first US compressed air energy storage (CAES) plant (110-MW-26 h) [Online], 1992. http://www.osti.gov/scitech/biblio/6843143.

E. Hakkarainen and M. Tähtinen. Dynamic Modelling and Simulation of Linear Fresnel Solar Field based on Molten Salt Heat Transfer Fluid. AIP Conf. Proc. 1734: 070014, 2016.

N. Hartmann, O. Vöhringer, C. Kruck, and L. Eltrop. Simulation and analysis of different adiabatic Compressed Air Energy Storage plant configurations. Applied Energy 93: 541-548, 2012.

S. Khaitan and M. Raju. Dynamic simulation of air-storage based gas turbine plants. International Journal of Energy Research 37(6): 558-569, 2013.

D. Kreid. Technical and economic feasibility analysis of the no-fuel compressed air energy storage concept [Online], 1976. http://www.osti.gov/scitech/biblio/7153562.

H. Le, S. Santoso, and T. Nguyen. Augmenting Wind Power Penetration and Grid Voltage Stability Limits Using ESS: Application Design, Sizing, and a Case Study. IEEE Trans. Power Syst. 27(1): 161-171, 2012.

X. Luo, J. Wang, C. Krupke, Y. Wang, Y. Sheng, J. Li, Y. $\mathrm{Xu}, \mathrm{D}$. Wang, S. Miao, and H. Chen. Modelling study, efficiency analysis and optimisation of large-scale Adiabatic Compressed Air Energy Storage systems with low-temperature thermal storage. Applied Energy 162: 589-600, 2016.

J. Manwell, J. McGowan, and A. Rogers. Wind characteristics and Resources. In Wind Energy Explained, 2nd ed. Chichester, United Kingdom: Wiley, 23-90, 2009.

L. Nielsen and R. Leithner. Dynamic Simulation of an Innovative Compressed Air Energy Storage Plant Detailed Modeling of the Storage Cavern. WSEAS Trans. Pow. Syst. 4(8): 253-263, 2009.

NREL. National Wind Technology Center: NWTC M2 Tower [Online], 2015. http://www.nrel.gov/midc/nwtc_m2/.

REN21. Renewables 2015 Global Status Report [Online], $2015 . \quad$ http://www.ren21.net/wpcontent/uploads/2015/07/REN12GSR2015_Onlinebook_low1.pdf.

SBC Energy Institute. Electricity Storage [Online], 2013. https://www.sbc.slb.com/ /media/Files/SBC\%20Energy\% 20Institute/SBC\%\%20Institute_Electricity_Storage $\% 20 \mathrm{Fa}$ ctbook_vf1.pdf.

R. Schulte, N. Critelli, K. Holst, and G. Huff. Lessons from Iowa: Development of a 270 Megawatt Compressed Air Energy Storage Project in Midwest Independent System $\begin{array}{ll}\text { Operator } & \text { [Online], }\end{array}$ http://www.sandia.gov/ess/publications/120388.pdf.

Solutia. Therminol VP-1 [Online], 1999. http://www.sintelub.com/files/therminol_vp1.pdf.

S. Succar and R. Williams. Compressed Air Energy Storage: Theory, Resources, And Applications For Wind Power [Online], 2008. https://www.princeton.edu/pei/energy/publications/texts/S uccarWilliams_PEI_CAES_2008April8.pdf.

S. Sundararagavan and E. Baker. Evaluating energy storage technologies for wind power integration. Solar Energy 86(9): 2707-2717, 2012. 
M. Tähtinen, T. Sihvonen, J. Savolainen, and R. Weiss. Interim H2 storage in Power-to-X Process: Dynamic Unit Process Modelling and Dynamic Simulations. In 10th Int. Renewable Energy Storage Conf. (IRES), 2016.

O. Weber. The Air-Storage Gas Turbine Power Station at Huntorf [Online], 1975. http://www.nrri.umn.edu/egg/REPORTS/CAES/Reference s/Weber.pdf.

Vestas Wind Systems. General Specification: V90-3.0 MW [Online], 2004. http://www.gov.pe.ca/photos/sites/envengfor/file/950010R 1_V90-GeneralSpecification.pdf.

D. Wolf and M. Budt. LTA-CAES - A low-temperature approach to Adiabatic Compressed Air Energy Storage. Applied Energy 125: 158-164, 2014.

World Energy Council. World Energy Scenarios: Composing energy futures to 2050 [Online], 2013. https://www.worldenergy.org/wpcontent/uploads/2013/09/World-Energy-

Scenarios_Composing-energy-futures-to-2050_Fullreport.pdf. 